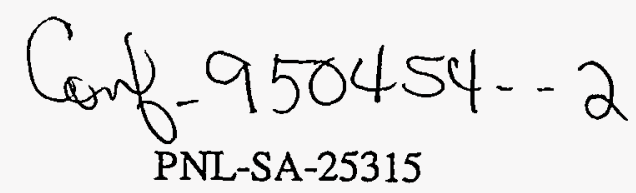

\title{
INFLUENCE OF PROCESSING VARIABLES ON THE STRUCTURE AND PROPERTIES OF ZnO FILMS
}

\author{
G. J. Exarhos \\ S. K. Sharma
}

April 1995

Presented at the

International Conference on Metallurgical Coatings and Thin Films April 23-28, 1995

San Diego, California

Prepared for

the U.S. Department of Energy

under Contract DE-AC06-76RLO 1830

Pacific Northwest Laboratory

Richland, Washington 99352

\section{DISCLAIMER}

This report was prepared as an account of work sponsored by an agency of the United States Government. Neither the United States Government nor any agency thereof, nor any of their employees, makes any warranty, express or implied, or assumes any legal liability or responsibility for the accuracy, completeness, or usefulness of any information, apparatus, product, or process disclosed, or represents that its use would not infringe privately owned rights. Reference herein to any specific commercial product, process, or service by trade name, trademark, manufacturer, or otherwise does not necessarily constitute or imply its endorsement, recommendation, or favoring by the United States Government or any agency thereof. The views and opinions of authors expressed herein do not necessarily state or reflect those of the United States Government or any agency thereof.

DISTRIBUTION OF THIS DOCUMENT IS UNLIMITED

OH

\section{MASTER}




\section{DISCLAIMER}

Portions of this document may be illegible in electronic image products. Images are produced from the best available original document. 


\title{
INFLUENCE OF PROCESSING VARIABLES ON THE STRUCTURE AND PROPERTIES OF ZnO FILMS
}

\author{
Gregory J. Exarhos, Pacific Northwest Laborataory \\ Shiv K. Sharma, University of Hawaii
}

\author{
Gregory J. Exarhos \\ Materials Sciences Department \\ Pacific Northwest Laboratory \\ PO BOS 999, MS K2-44 \\ Richland, WA 99352 \\ phone: (509) 375-2440 \\ fax: (509) 375-2186 \\ e-mail: gj_exarhos@pnl.gov
}

\author{
Shiv K. Sharma \\ University of Hawaii \\ 2525 Correa Road \\ Hawaii Inst. Of Geophysics \& Planet. \\ Honolulu, HI 96822 \\ phone: (808) 956-8476 \\ fax: (808) 956-2539 \\ e-mail:·sksharma@soest.hawaii.edu
}

\section{Abstract}

Zinc oxide films of high optical quality have been deposited onto both silica and silicon substrates using reactive sputtering, pulsed laser deposition, and an aqueous solution based technique. Films have been characterized with respect to crystalline phase and phase stability, surface morphology, and optical response by means of $X$ ray diffraction, Raman Spectroscopy, Atomic Force Microscopy, optical transmission and ellipsometry measurements. All films studied were of the wurtzite phase, finegrained, and exhibited varying degrees of c-axis orientation with respect to the substrate normal depending upon deposition conditions. Films showed some degree of residual tensile stress which was inferred from the $\mathrm{E}_{2}$ Raman line shift relative to the single crystal frequency. The wurtzite phase was found to be stable to temperatures near $800^{\circ} \mathrm{C}$, but at higher temperatures, reaction with silica led to evolution of $\mathrm{Zn}_{2} \mathrm{SiO}_{4}$ at the interface. Variations in Raman line intensities upon post deposition annealing has been correlated with oxidation of excess zinc in the lattice.

Keywords: orientation, laser deposition, Raman spectroscopy, sputtering, zinc oxide 


\section{INFLUENCE OF PROCESSING VARIABLES ON THE STRUCTURE AND PROPERTIES OF ZnO FILMS}

Gregory J. Exarhos, Pacific Northwest Laboratory, Richland, WA 99352 Shiv K. Sharma, University of Hawaii, Honolulu, HI 96822

\section{Abstract}

Zinc oxide films of high optical quality have been deposited onto both silica and silicon substrates using reactive sputtering, pulsed laser deposition, and an aqueous solution based technique. Films have been characterized with respect to crystalline phase and phase stability, surface morphology, and optical response by means of $X$ ray diffraction, Raman Spectroscopy, Atomic Force Microscopy, optical transmission and ellipsometry measurements. All films studied were of the wurtzite phase, finegrained, and exhibited varying degrees of $c$-axis orientation with respect to the substrate normal depending upon deposition conditions. Films showed some degree of residual tensile stress which was inferred from the $\mathrm{E}_{2}$ Raman line shift relative to the single crystal frequency. The wurtzite phase was found to be stable to temperatures near $800^{\circ} \mathrm{C}$, but at higher temperatures, reaction with silica led to evolution of $\mathrm{Zn}_{2} \mathrm{SiO}_{4}$ at the interface. Variations in Raman line intensities upon post deposition annealing has been correlated with oxidation of excess zinc in the lattice.

Keywords: orientation, laser deposition, Raman spectroscopy, sputtering, zinc oxide

\section{Introduction}

Increased technical activity has been directed toward both the deposition and characterization of zinc oxide films owing to the multifunctional properties such films exhibit. In addition to optical transparency throughout the visible region of the spectrum and the observed large piezooptic and piezoelectric effects in films which are c-axis oriented, trivalent cation-doped $\mathrm{ZnO}$ exhibits marked electrical conductivity. The combination of these characteristics makes zinc oxide a system of choice for thin film opto-electronic device applications.

Zinc oxide films have been prepared using both vapor and solution deposition techniques. Wurtzite films derived using reactive sputtering methods usually exhibit 
preferred c-axis grain orientation normal to the substrate surface. The grain size, lattice strain, and extent of orientation in these films can be modified through post deposition annealing [1]. Film growth rate and the extent of crystallite orientation also were observed to depend upon if power density, substrate temperature, and precursor chemistry in PECVD deposited films [2]. In this earlier work, films deposited, even at temperatures below $200^{\circ} \mathrm{C}$, showed a high degree of orientation. Films prepared by magnetron sputtering methods also exhibited strong c-axis orientation [3]. The magnetron deposition route has been shown to be effective for preparing doped $\mathrm{ZnO}$ films which exhibit marked electrical conductivity [4,5]. High optical quality and electrically conducting $\mathrm{ZnO}$ films have been prepared as well using pulsed laser deposition methods [6]. This recent work described the formation of a dense columnar microstructure in films deposited at temperatures below $350^{\circ} \mathrm{C}$ with concomitant high optical transmission of visible light. Good quality films also have been prepared by means of spray pyrolysis and hydrothermal deposition techniques $[7,8,9]$. Again caxis orientation of the wurtzite phase was verified through $\mathrm{x}$-ray diffraction measurements. Dopant additions were found to influence not only the film conductivity, but the crystallite phase and orientation as well.

Work reported here concerns the characterization of pure $\mathrm{ZnO}$ films deposited by reactive sputtering, pulsed laser deposition, and aqueous solution deposition routes. Highly c-axis oriented films were prepared using both sputtering and laser deposition routes although the degree of orientation was less in sputtered thick films. Spin cast films were prepared from water solutions containing zinc nitrate in the presence of glycine which acts as a cation complexant in accord with an earlier described method [10]. Following annealing at moderate temperatures to evolve the wurtzite phase, preferential c-axis orientation was not found. Films deposited using all of these routes were of high optical quality and exhibited relatively flat surface textures as seen in atomic force micrographs. Raman spectra of thin $\mathrm{ZnO}$ films are reported in this work for the first time and unambiguously identify the wurtzite phase in all cases. In addition, measured phonon frequency shifts from those observed in the single crystal can be used to estimate residual film stress and how it changes with deposition 
method [11]. Raman line intensity anomalies observed in thick sputtered films are attributed to the presence of excess zinc in the lattice and signify presence of a metal rich defect state. The results of this study suggest that Raman methods can be used to rapidly ascertain film crystalline phase, residual film stress, and the presence of excess zinc in the structure.

\section{Experimental}

\subsection{Film deposition procedures}

Pure zinc oxide films were prepared by means of reactive sputter deposition, pulsed laser deposition, and aqueous solution deposition routes. Reactively sputtered films were deposited onto cleaned silica substrates in an $\mathrm{Ar} / \mathrm{O}_{2}$ gas mixture using an RF power of 150 Watts. The substrates were located approximately $25 \mathrm{~cm}$ from the zinc metal target and rotated in a planetary fashion. The total pressure during sputtering was $1.5 \mathrm{mTorr}$ and a 30 percent oxygen composition was used. Uniform film thickness on the order of 6 quarter waves was registered through optical monitoring at $550 \mathrm{~nm}$. Films alșo were deposited onto cleaned silica and silicon substrates by a laser deposition method. Pulsed irradiation at $248 \mathrm{~nm}\left(1.5 \mathrm{~J} / \mathrm{cm}^{2}\right)$ of a $99.9 \%$ pure ZnO target in 40 mTorr of oxygen generated films having a thickness on the order of 5 quarter waves at $550 \mathrm{~nm}$. Substrates were held at room temperature and the target to substrate distance was $5 \mathrm{~cm}$. In addition to preparing ZnO films using vacuum deposition methods, films also were derived from an aqueous precursor solution prepared by combining $6.0 \mathrm{gms}$ of $\mathrm{Zn}\left(\mathrm{NO}_{3}\right)_{2} \cdot 6 \mathrm{H}_{2} \mathrm{O}$ and $2.25 \mathrm{gms}$ of glycine $\left(\mathrm{H}_{2} \mathrm{NCH}_{2} \mathrm{COOH}\right)$ with $20 \mathrm{gms}$ of deionized water. The solution was stirred and heated at $80^{\circ} \mathrm{C}$ for 1 hour, then cooled and passed through a $0.45 \mu \mathrm{m}$ nucleopore filter prior to spin casting onto cleaned silica or silicon substrates at $3500 \mathrm{rpm}$ for $50 \mathrm{sec}$ at room temperature. Upon heating to $400^{\circ} \mathrm{C}$, residual nitrate completely oxidized the organic glycine matrix and the wurtzite crystalline phase of $\mathrm{ZnO}$ evolved. Several films prepared by each technique also were subjected to post deposition annealing in air at temperatures up to $1000^{\circ} \mathrm{C}$ to investigate phase stability. 


\subsection{Film characterization methods}

Film thickness and optical constants were determined by means of optical spectroscopy and ellipsometry. Transmission spectra of films deposited on silica were recorded from $200 \mathrm{~nm}$ to $2500 \mathrm{~nm}$ using a Varian Cary Model 5 double beam recording spectrophotometer. Observed fringes were analyzed using the method of Manifacier, et al [12]. Refractive index and thickness also were determined for films deposited on silicon substrates from ellipsometric measurements using a modified Gartner instrument. A $632.8 \mathrm{~nm}$ probe beam at $70^{\circ}$ incidence to the film surface was used. Parameters derived using both methods agreed to within $\pm 2 \%$ which illustrates the uniformity of the coatings obtained by the different deposition methods. AFM images measured on a Nanoscope 3 using a silicon nitride tip were used to characterize crystallite grain size and to evaluate surface roughness.

A Phillips APD 3620 diffractometer equipped with a scintillation detector was used to record $x$-ray diffraction patterns of deposited films in order to evaluate crystalline phase and crystallite orientation. A fixed $\mathrm{Cu}$ anode operating at $40 \mathrm{keV}$ and $45 \mathrm{~mA}$ served as the $\mathrm{x}$-ray source. The anode was equipped with a graphite monochromator which allowed separation of the $\mathrm{Cu} K \alpha_{1}$ and $\mathrm{K} \alpha_{2}$ radiation and a $2 \theta$ compensating slit which maintained a small spot size throughout the $2 \theta$ scans over a range from $5^{\circ}$ to $75^{\circ}$. Data were obtained using a resolution of $.05^{\circ}$ with a $3 \mathrm{sec}$ integration time per point.

Raman microprobe spectra of coated substrates were acquired using a $180^{\circ}$ backscattering geometry with the sample film to be analyzed located at the focal plane of a Zeiss microscope interfaced to the spectrometer. Approximately $100 \mathrm{~mW}$ of $\mathrm{cW}$ excitation from an argon ion laser was imaged onto each sample using a 40 power objective ( $n a=0.60$ ). Scattered light collected by the microscope was directed and focused onto the entrance slits of a SPEX model 1877 triple spectrometer. The filtered dispersed light was measured using a liquid nitrogen cooled CCD detector (Princeton Instruments). Excitation wavelengths used were $457.9 \mathrm{~nm}, 488.0 \mathrm{~nm}$, and $514.5 \mathrm{~nm}$. Exposure times ranged from several seconds to several hundred seconds. The array 
was calibrated using the known vibrational frequencies of a $\mathrm{TiO}_{2} / \mathrm{Na}_{2} \mathrm{SO}_{4}$ standard.

\section{Results}

Films deposited by reactive sputter deposition, laser deposition, or by spin casting of the aqueous precursor solution described in section 2.2 all showed excellent transmission (in excess of $85 \%$ ) in the visible region of the spectrum with a steep fall-off in transmission at ca $380 \mathrm{~nm}$ as shown in Figure 1 for several representative samples. (Weak absorption features near 1400 and $2200 \mathrm{~nm}$ are ascribed to residual $-\mathrm{OH}$ in the silica substrate.) Refractive indices for sputtered and solution-deposited films which range from 1.98 to 2.02 are somewhat higher than that of laser deposited films (1.92) suggesting the presence of a higher void content in the latter film. This was expected for room temperature deposited films since pulsed laser deposition onto heated substrates is known to generate films with higher indices [6]. All films showed extinction coefficients less than $5 \times 10^{-3}$ at wavelengths greater than $450 \mathrm{~nm}$.

The observed high transmissivity of these films suggests that film surfaces are relatively smooth. Figure 2 illustrates the surface morphology measured using AFM for three different films. Surface roughness is lowest for the pulsed laser deposited films and is somewhat larger for the sputtered and solution deposited films. Observed features are less than $10 \%$ in size of the wavelength of visible light which contributes to the high optical throughput and low scatter.

- X-ray diffraction meașurements of deposited films were obtained to identify the resident crystal phase of $\mathrm{ZnO}$ and to verify whether grain orientation was present. The diffraction patterns for films deposited from solution, and prepared using both ifsputtering and laser deposition methods are shown in Figure $3 a-3 d\left(30^{\circ}<2 \Theta<75^{\circ}\right)$ along with the crystal structure of the (hexagonal) wurtzite phase of $\mathrm{ZnO}$ (Figure 3f). The solution deposited $\mathrm{ZnO}$ film, having a thickness less than $100 \mathrm{~nm}$, exhibits a relatively weak diffraction pattern which indicates some degree of $\mathrm{c}$-axis ordering normal to the surface. The high intensity in the (101) reflection and medium intensity of the (102), (110), (103), and (112) reflections also is seen in randomly oriented 
powder samples. Laser deposited and thin sputter deposited films exhibit virtually identical diffraction patterns characteristic of a highly oriented (c-axis normal to the substrate) wurtzite phase and in concurrence with results obtained previously [6]. Only the (002) and (004) diffraction lines are evident. The FWHM of the (002) diffraction feature corrected with respect to instrumental broadening is $0.19^{\circ}$ attesting to the high degree of crystallite orientation. In significantly thicker $(8 \mu \mathrm{m}) \mathrm{r}$-sputtered films, c-axis ordering is degraded as shown in Figure $3 \mathrm{~d}$. This diffraction pattern is identical to the pattern observed for annealed $\mathrm{ZnO}$ films prepared using a hydrothermal deposition route [9].

$\mathrm{ZnO}$ films deposited on silica appear to be stable in air when heated to temperatures at or below $800^{\circ} \mathrm{C}$. For example, heating of the thick if-sputtered film to $800^{\circ} \mathrm{C}$ for 16 hours does not change the number or relative intensity of obsered lines, but a $50 \%$ decrease in all linewidths is seen. When heated to higher temperatures, however, chemical interaction with the $\mathrm{SiO}_{2}$ substrate is likely. For example, Figure $3 e$ shows the diffraction pattern $\left(5^{\circ}<2 \Theta<75^{\circ}\right)$ of a solution deposited $\mathrm{ZnO}$ film on silica following heating to $1000^{\circ} \mathrm{C}$. Lines characteristic of the wurtzite phase are absent, but diffraction features characteristic of $\mathrm{Zn}_{2} \mathrm{SiO}_{4}$ are now evident. At these temperatures zinc diffusion occurs readily leading to irreversible formation of a new phase.

An alternate route to characterization of the crystalline phase of a material is afforded through Raman scattering measurements. In addition to the identification of phase and phase homogeneity, the attendant residual film stress can be estimated from measured line shifts. Raman spectra excited with $488 \mathrm{~nm} \mathrm{cw}$ laser radiation at normal incidence to $\mathrm{ZnO}$ films deposited on silica and measured in the Raman microprobe are shown in Figure 4 along with the Raman spectrum for a wurtzite powder sample. Raman scattering attributed to the silica substrate has been subtracted from all measured film spectra. Measured Raman spectra from solution deposited, laser deposited and thin rf-sputtered films are quite weak as a result of the relatively small crystallite grain size and submicrometer film thickness. Previous work demonstrated that certain Raman mode intensities can be resonantly enhanced in 
ZnO crystals as the probe excitation energy approaches the bandgap energy [13]. These findings have been verified in this work for thin films deposited on both silica and silicon substrates. Nonetheless, even under non-resonance excitation, features characteristic of the wurtzite phase (particularly the appearance of the $437 \mathrm{~cm}^{-1} \mathrm{E}_{2}$ mode) easily are discernible. The thick sputtered film also exhibits features characteristic of the wurtzite phase. However, the $E_{1}(L O)$ mode intensity at $579 \mathrm{~cm}^{-1}$ is anomalously high. While differences in crystallite orientation may account for some perturbation to relative line intensities [14,15], modes of the same symmetry should exhibit similar intensity perturbations. The origin of the intensity anomaly may reside in the presence of excess zinc in the lattice introduced as a result of the increased time required to sputter the thicker film.

Vibrational mode frequency shifts relative to the single crystal value can be used to estimate residual stress in thin films [11]. The pressure dependence of the high frequency $\mathrm{E}_{2}$ mode in $\mathrm{ZnO}$ (wurtzite) is $+0.52 \mathrm{~cm}^{-1} / \mathrm{kbar}$ as determined by Mitra, et al [16]. Based upon this result, the residual stress for all $\mathrm{ZnO}$ films deposited in this work is estimated to be on the order of 4 to 8 kbar tensile. Films can be ranked according to residual tensile stress in the following order: if-sputtered < solution deposited < laser ablated.

\section{Discussion}

$\mathrm{ZnO}$ films have been prepared by sputter and laser deposition processes and by a new aqueous solution processing route. Both the thin sputter deposited and laser deposited films exhibit properties comparable to those reported in the literature for films prepared using the same deposition methods and similar deposition conditions. For example, these films are highly c-axis oriented normal to the surface as seen in the $x$-ray diffraction traces shown in Figure 3 . The water-based deposition process described previously [17], involves coordination of zinc cations in an organic glass forming matrix along with nitrate counterions. Following solvent removal during spin casting of films, $\mathrm{Zn}+2$ and nitrate anions become homogeneously distributed in an amorphous glycine matrix. Subsequent heating initiates oxidation of the organic 
complexant by nitrate which also is resident in the matrix to form the pure zinc oxide phase. Such films do not show the extent of c-axis ordering evident in rf-sputtered or laser deposited $\mathrm{ZnO}$ films, but a significant degree of $\mathrm{c}$-axis ordering is still present. The diffraction trace shown in Figure $3 a$ indicates that the solution derived film has both c-axis orientation normal to the surface and random ordering as would be observed in a powder sample. The diffraction linewidths also are somewhat broader when compared with the laser deposited or thin sputtered film linewidths again indicating a lower degree of orientation. Thick sputtered films show preferred orientation in the (100) crystal direction, which is in contrast to the crystallite orientation observed in all the other films. This diffraction pattern is nearly identical to that of hydrothermally prepared $\mathrm{ZnO}$ where the hexagonal faces of the crystal unit cell were found to be normal to the substrate surface. Increased diffraction linewidths may be indicative of the presence of lattice defects [9].

The Raman spectrum of the thick sputtered film reveals increased intensity in the $579 \mathrm{~cm}^{-1} E_{1}$ mode relative to the $437 \mathrm{~cm}^{-1} E_{2}$ mode when compared with the Raman spectrum of a powder sample. Post deposition annealing studies have been carried out in an effort to understand this intensity anomaly. Raman spectra of the thick sputtered film as a function of annealing time and temperature are shown in Figure 5. A marked decrease in the $579 \mathrm{~cm}^{-1}$ mode intensity relative to the $E_{2}$ mode intensity is observed with annealing. Also, the linewidth of the $E_{2}$ mode decreases from about $16.3 \mathrm{~cm}^{-1}$ to about $6.6 \mathrm{~cm}^{-1}$. The observed $1 \mathrm{~cm}^{-1}$ increase in resonance frequency suggests that the residual stress in the film has become less tensile.

Two possible explanations for the observed Raman intensity anomaly involve thermally-induced crystallite reorientation or resonance enhancement of selective phonon modes due to lattice impurities. Post deposition annealing is known to altercrystallite orientation in hydrothermally deposited films [9]. X-ray diffraction measurements of the if-sputtered thick film reveal no change in the number and relative line intensities following annealing but a marked narrowing of the diffraction features is evident. Therefore, no crystallite reorientation has occurred although crystallite grain sizes necessarily have increased. The second explanation of the line 
intensity anomaly requires a presence of excess zinc in the film which would introduce defect electronic states within the bandgap. The $E_{1}(L O)$ mode does indeed show resonance Raman enhancement in stoichiometric $\mathrm{ZnO}$ [13]. It is proposed here, that the impurity states introduced by the excess zinc in the film stimulate the onset of resonance enhancement at longer wavelengths (eg $488 \mathrm{~nm}$ ) than seen in the stoichiometric material. A zinc rich film could be formed during sputtering of the thick coating owing to the significantly longer sputtering time required to deposit the film and increased opportunity for oxygen outgassing of the film or atomic zinc incorporation. Selective resonance Raman enhancement of the $\mathrm{E}_{1}(\mathrm{LO})$ mode, then, is a likely explanation for the observed intensity anomaly. Upon annealing in air, excess zinc in the film becomes oxidized, the impurity states disappear, and the magnitude of resonance Raman enhancement of the $E_{1}(L O)$ mode is diminished.

\section{Conclusions}

Fine-grained, high optical quality $\mathrm{ZnO}$ films have been deposited on silica substrates using rf-sputtering, pulsed laser deposition, and aqueous solution techniques. Refractive indices were found to vary with deposition method and are lower for the pulsed laser deposited films investigated here probably because the deposition was carried out with substrates held at room temperature. However, a high degree of c-axis orientation with respect to the substrate normal has been found not only in these laser deposited films, but in thin rf-sputtered films as well. The orientation appears to degrade as film thickness increases to several micrometers. Solution deposited films exhibit a lesser degree of ordering and show chemical reactivity with silica substrates to form a $\mathrm{Zn}_{2} \mathrm{SiO}_{4}$ phase when heated to $1000^{\circ} \mathrm{C}$. Films prepared by all of these deposition methods are of the wurtzite phase and exhibit some degree of residual tensile stress as determined from relative shifts in phonon line frequencies determined from Raman spectra. Work reported here represents the first observation of Raman scattering in submicrometer $\mathrm{ZnO}$ films and suggests the viability of this technique for rapid characterization of $\mathrm{ZnO}$ films with respect to phase, phase homogeneity, residual stress, and impurity content. 


\section{Acknowledgements}

This work has been supported by the Materials Sciences Division of the Office of Basic Energy Sciences, US Department of Energy. Pacific Northwest Laboratory is operated by Battelle Memorial Institute for the US Department of Energy under Contract DE-AC06-76RLO 1830. A faculty research fellowship provided through the Associated Western Universities Northwest Division is gratefully acknowledged by SKS. The authors also wish to express their appreciation to Dr. Chris Coronado for preparing the sputter deposited films and to Dr. Michael Geusic for preparing the pulsed laser deposited films. In addition, Dr. Li-Qiong Wang is acknowledged for her assistance in acquiring the atomic force images, and Mr. David McCready is thanked for his assistance in obtaining the x-ray diffraction data. 


\section{References}

[1] O. Nennewitz, H. Schmidt, J. Pezoldt, Th. Stauden, J. Schawohl, and L. Spiess, phys. Stat. Sol. (a) 145: 283 (1994).

[2] . Y.J. Kim and H.J. Kim, Materials Letters 21: 351 (1994).

[3] S. Takada, J. Appl. Phys. 73(10): 4739 (1993).

[4] F.S. Mahmood and R.D. Gould, Thin Solid Films 253: 529 (1994).

[5] K. Tominaga, M. Kataoka, T. Ueda, M. Chong, Y. Shintani, and I. Mori, Thin Solid Films 253: 9 (1994).

[6] V. Craciun, J. Elders, J.G.E. Gardeniers, and I.W. Boyd, Appl. Phys. Lett. 65(23):2963 (1994).

[7] A. Tiburcio-Silver, J.C. Joubert, and M. Labeau, J. Appl. Phys. 76(3):1992 (1994).

[8] P. Pushparajah, A.K. Arof, and S. Radhakrishna, J. Phys. D: Appl. Phys. 27:1518 (1994).

[9] Q. Chen, Y. Qian, Z. Chen, G. Zhou, and Y. Zhang, Materials Letters 22: 93 (1995).

[10] G.J. Exarhos, L.Q. Wang, and T. Dennis, Thin Solid Films 253: 41 (1994).

[11] G.J. Exarhos and N.J. Hess, Thin Solid Films 220: 254 (1992).

[12] J.C. Manifacier, J. Gasiot, and J.P. Fillaird, J. Phys. E: Sci. Instrum. 9: 4002 (1976).

[13] J.M. Calleja and M. Cardona, Phys. Rev B 16(8): 3753 (1977).

[14] T.C. Damen, S.P.S. Porto, and B. Tell, Phys. Rev. 142: 570 (1966).

[15] C.A. Arguello, D.L. Rousseau, and S.P.S. Porto, Phys. Rev.181(3):1351 (1969).

[16] S.S. Mitra, O. Brafman, W.B. Daniels, and R.K. Crawford, Phys. Rev. 186(3): 942 (1969).

[17] L.R. Pederson, L.A. Chick, and G.J. Exarhos, Preparation of thin ceramic films via an aqueous solution route, U.S. Patent 4,880,772 (1989). 


\section{Figure Captions}

Figure 1. Optical transmission spectra of $\mathrm{ZnO}$ films deposited on silica substrates. (a) solution deposited; (b) pulsed laser deposited; and (c) rf-sputtered.

Figure 2. AFM images of the $\mathrm{ZnO}$ films deposited on silica shown in Figure 1. (a) solution deposited; (b) pulsed laser deposited; and (c) if-sputtered.

Figure 3. X-ray diffraction patterns of $\mathrm{ZnO}$ films deposited on silica with principal reflections for the wurtzite phase indicated. (a) solution deposited; (b) pulsed laser deposited film; (c) rf-sputtered thin film; (d) $8.0 \mu \mathrm{m}$ rfsputtered thick film; (e) solution deposited film heated to $1000^{\circ} \mathrm{C}$ for 1 hour in air; and (f), the crystal structure of the $\mathrm{ZnO}$ hexagonal wurtzite phase.

Figure 4. Laser Raman spectra of $\mathrm{ZnO}$ films on silica and a powder sample of the wurtzite crystalline phase all excited at $488 \mathrm{~nm}$. (a) solution deposited $\left[V\left(E_{2}\right)=435 \mathrm{~cm}^{-1}\right]$; (b) pulsed laser deposited film $\left[V\left(E_{2}\right)=434 \mathrm{~cm}^{-1}\right]$; (c) rf-sputtered thin film $\left[V\left(E_{2}\right)=436 \mathrm{~cm}^{-1}\right]$; (d) $8.0 \mu \mathrm{m}$ rf-sputtered thick film; and $\left[V\left(E_{2}\right)=436 \mathrm{~cm}^{-1}\right](e)$ powder sample $\left[V\left(E_{2}\right)=438 \mathrm{~cm}^{-1}\right]$.

Figure 5. Laser Raman spectra of the $8.0 \mu \mathrm{m}$ rf-sputtered thick film on silica excited at $488 \mathrm{~nm}$ following heating in air for different times. (a) as-deposited film; (b) heat treated at $450^{\circ} \mathrm{C}$ for 1 hour; (c) heat treated at $450^{\circ} \mathrm{C}$ for 1 hour followed by heating at $800^{\circ} \mathrm{C}$ for 8 hours; (d) heat treated at $450^{\circ} \mathrm{C}$ for 1 hour followed by heating at $800^{\circ} \mathrm{C}$ for 16 hours; (e) wurtzite phase ZnO powder sample. 


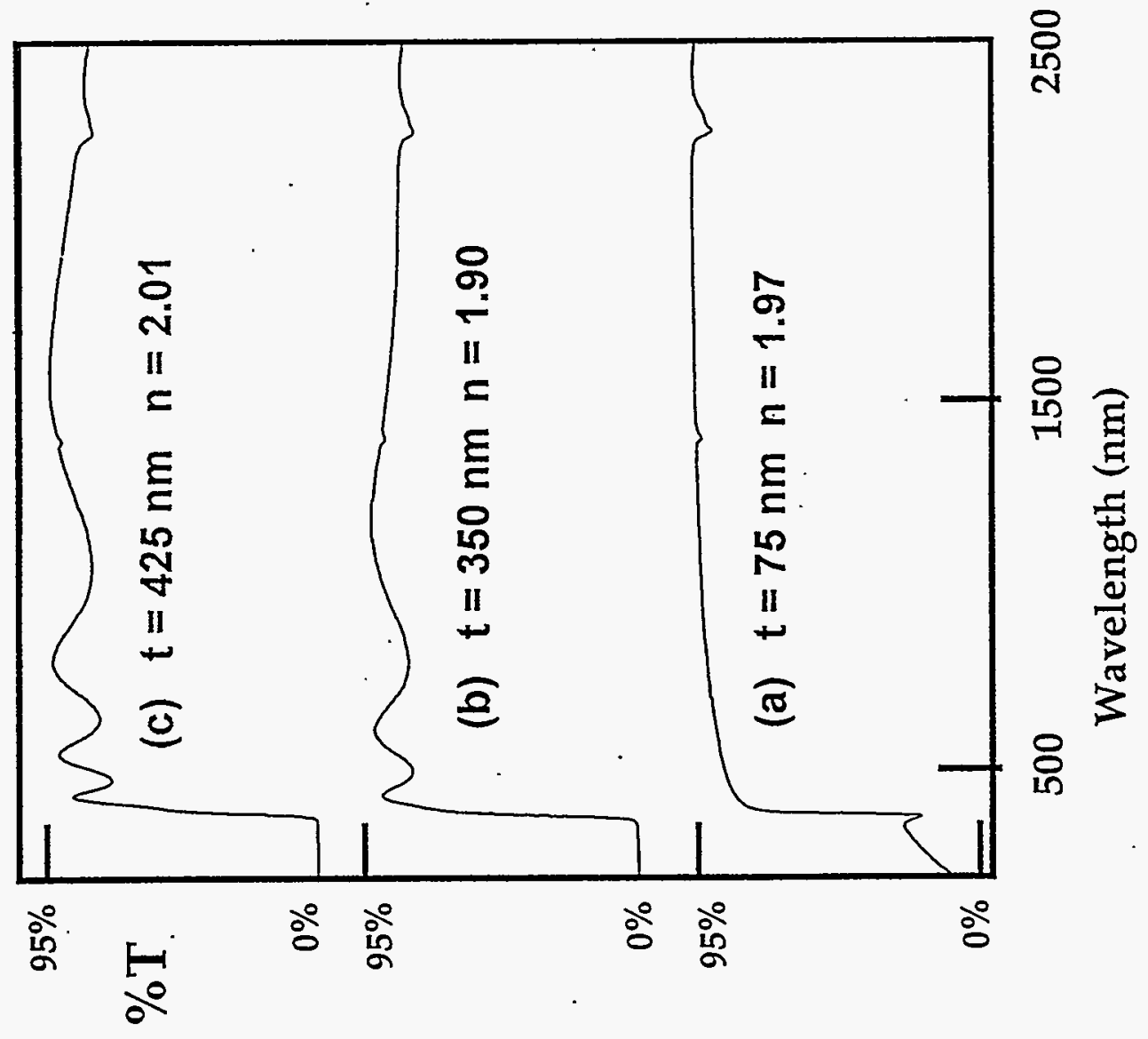




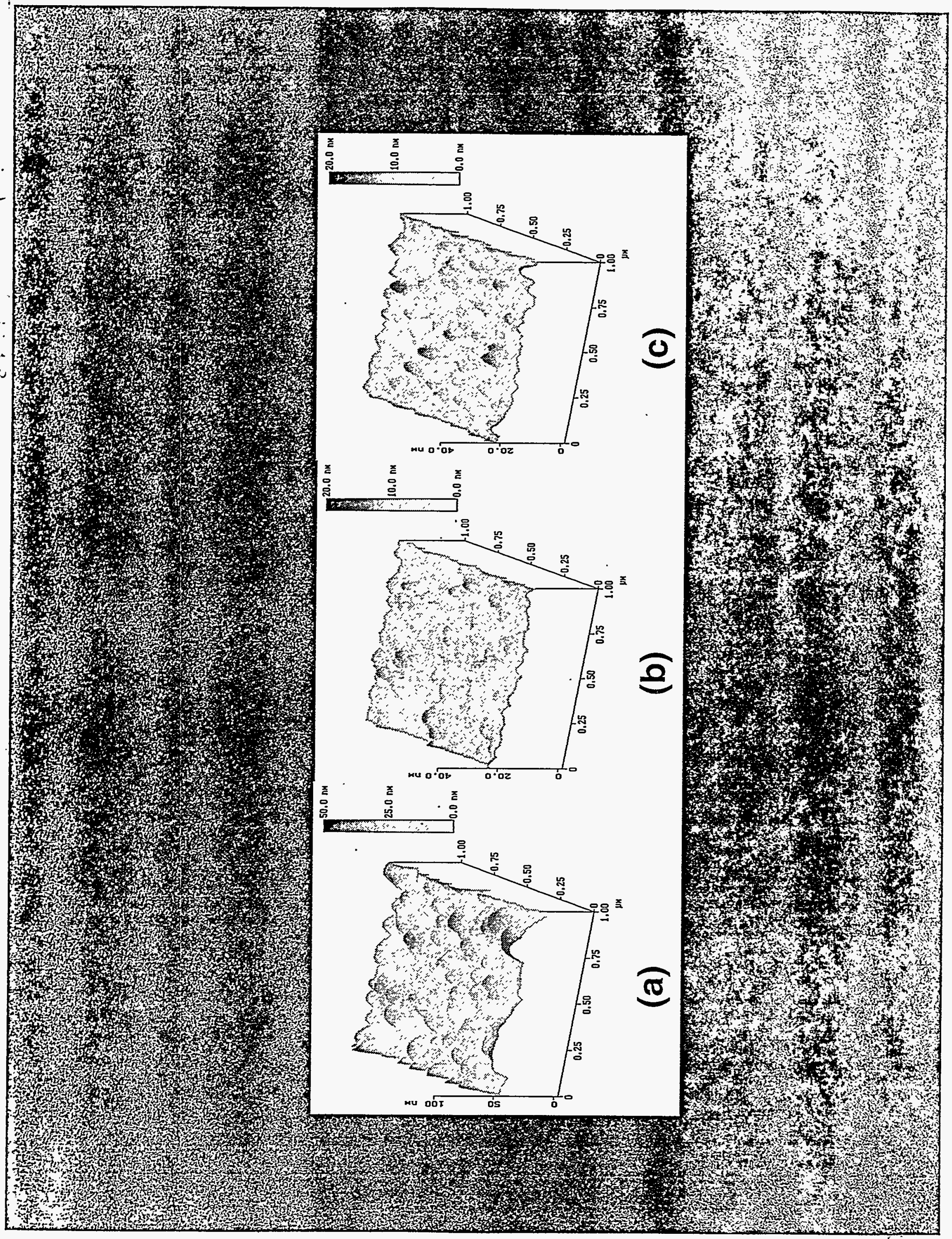




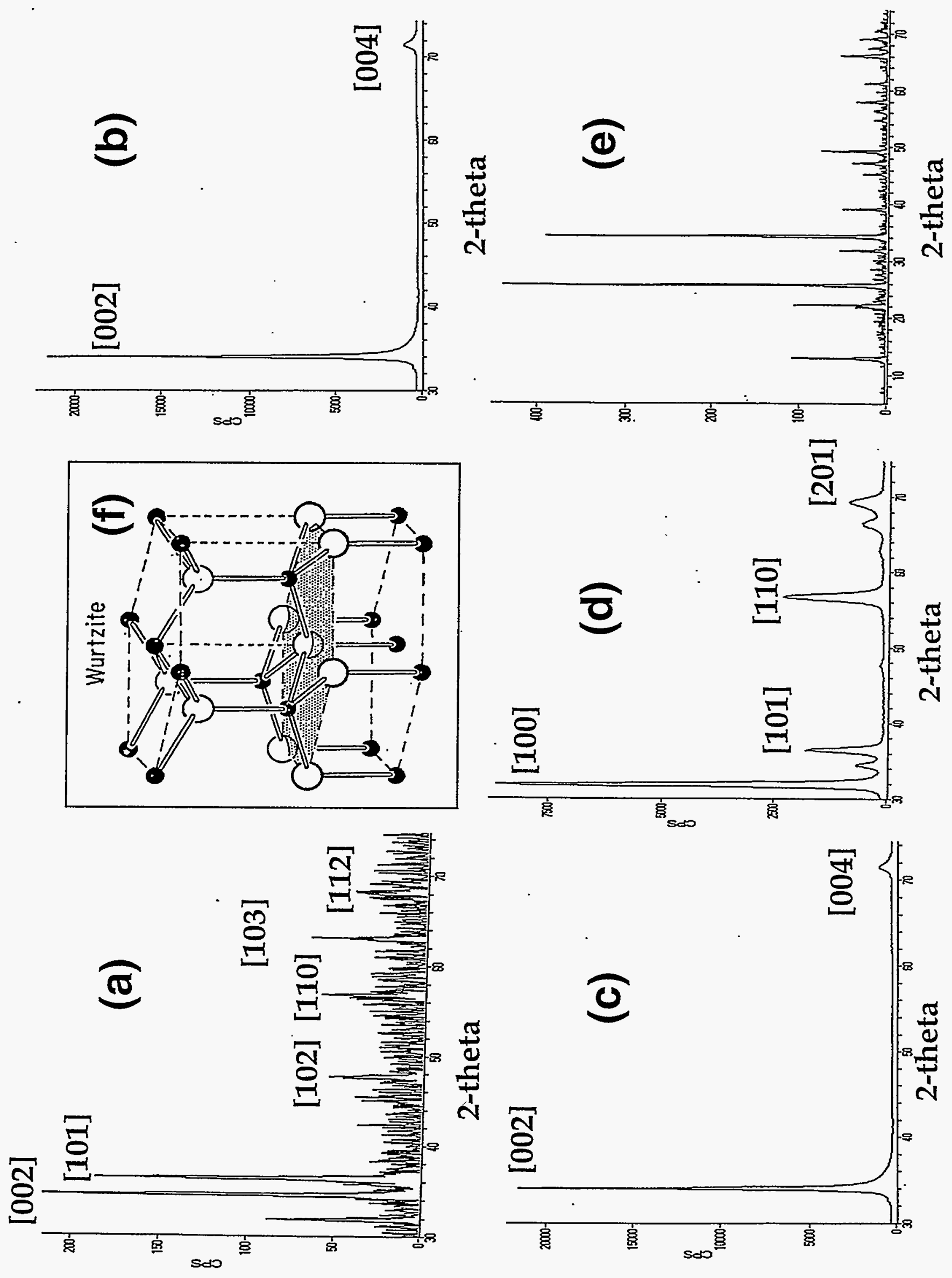




\section{(e)}
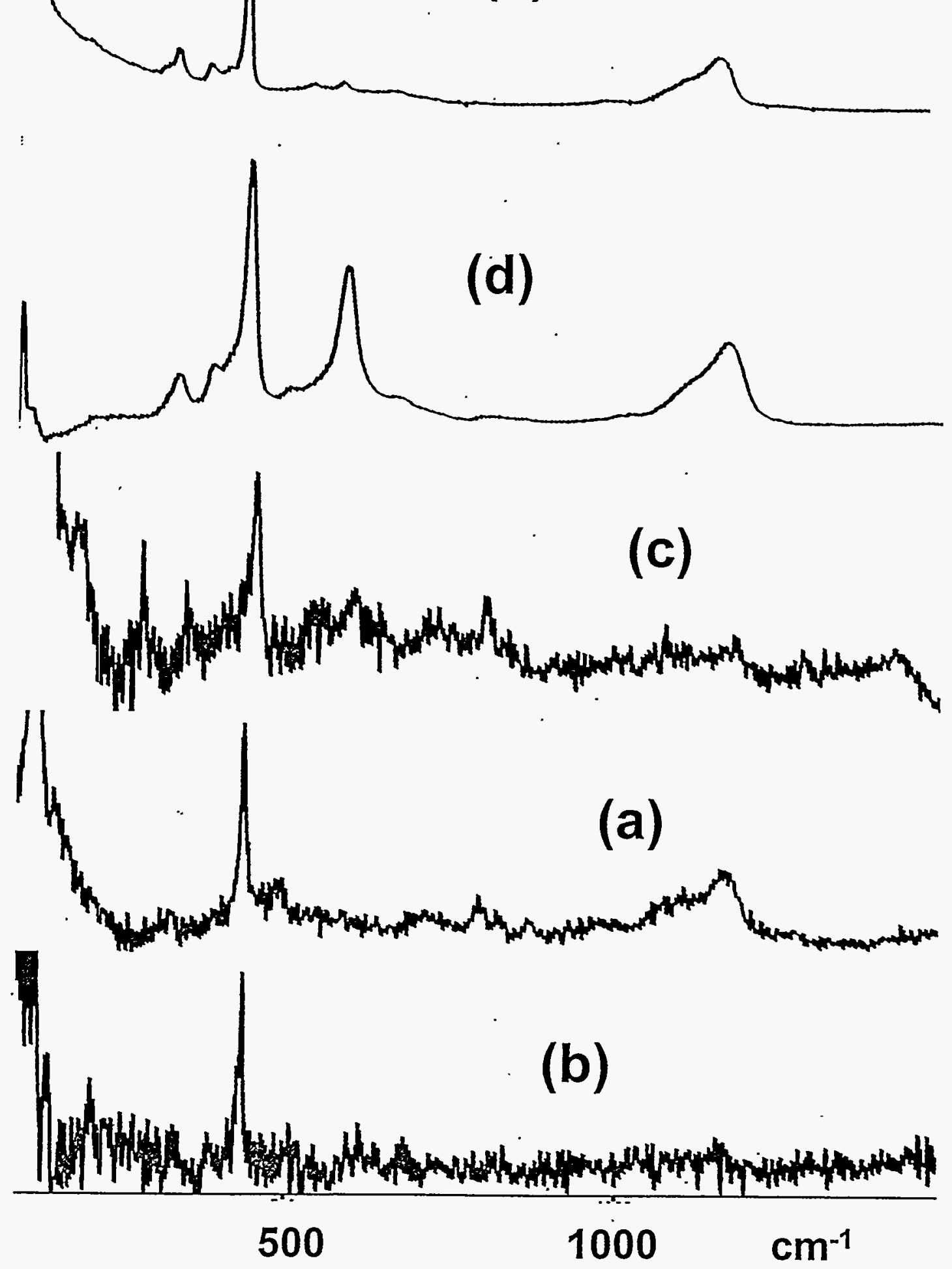

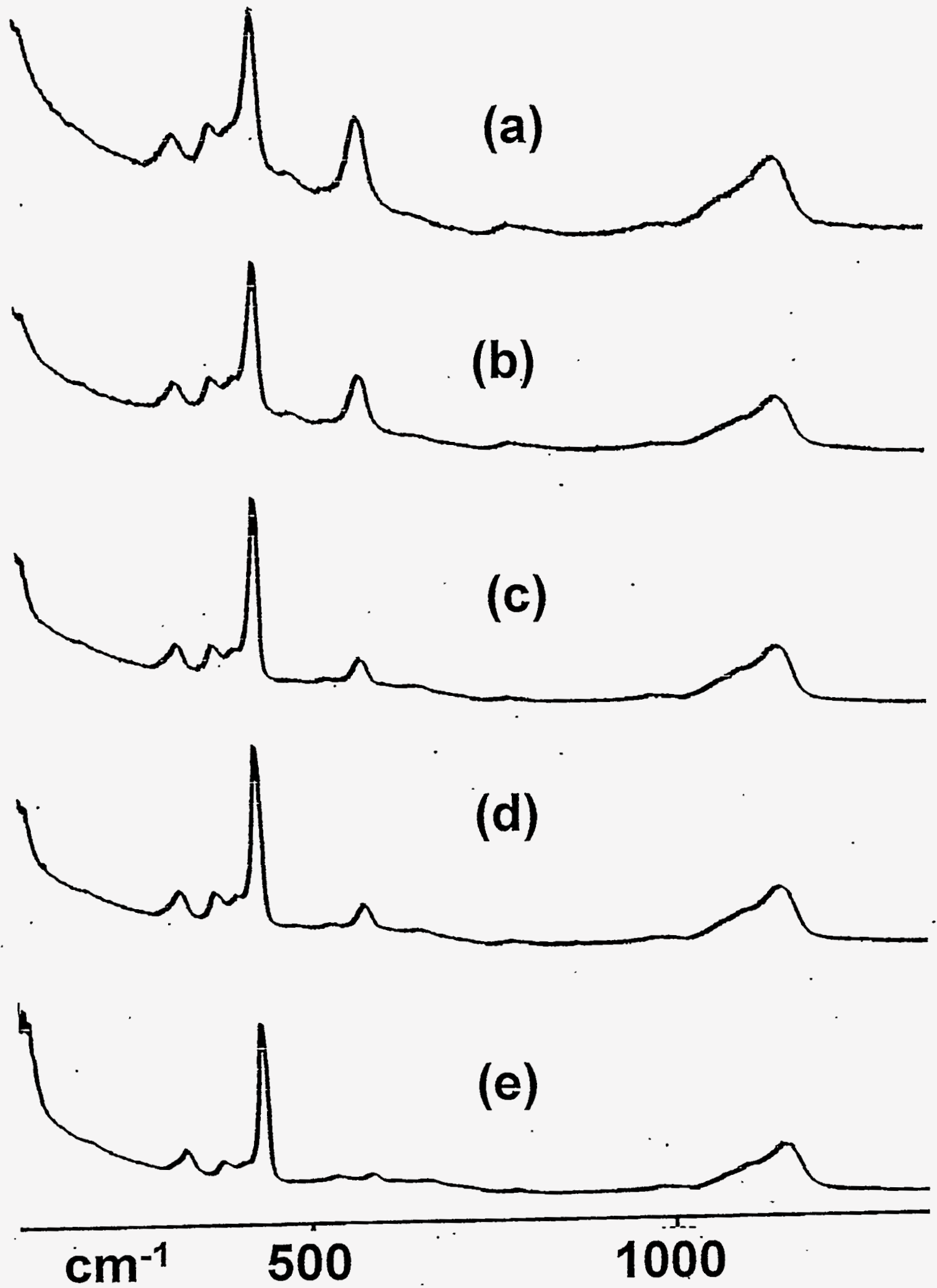